\title{
Forced-Air-Cooled 10 kW Three-Phase SiC Inverter with Output Power Density of more than 20 kW/L
}

\author{
Shinji Sato ${ }^{1,2}$, Kohei Matsui ${ }^{1,3}$, Yusuke Zushi ${ }^{1,4}$, Yoshinori Murakami ${ }^{1,4}$, \\ Satoshi Tanimoto ${ }^{1,4}$, Hiroshi Sato ${ }^{1,5}$ and Hiroshi Yamaguchi ${ }^{1,5}$ \\ ${ }^{1} 3$ rd R\&D Center, FUPET, c/o AIST, Central 2-10, 1-1-1, Umezono, Tsukuba 305-8568, Japan \\ ${ }^{2}$ Sanken Electric Co., Ltd., 3-6-3, Kitano, Niiza-shi, Saitama 352-8666, Japan \\ ${ }^{3}$ Fuji Electric Holdings Co, Ltd., Fuji-machi, Hino-shi, Tokyo 191-8502, Japan \\ ${ }^{4}$ Nissan Motor Co., Ltd., 1, Natsushima-cho, Yokosuka 237-8523, Japan \\ ${ }^{5}$ ADPERC, AIST, Central 2, 1-1-1, Umezono, Tsukuba 305-8568, Japan \\ shinji-satou@aist.go.jp
}

Keywords: output power density, three-phase inverter system, all SiC inverter, power module, gate driving technique.

\begin{abstract}
A forced-air-cooled three-phase inverter built with SiC-JFETs and -SBDs as power semiconductor devices was designed and fabricated. The inverter can operate steadily at a rated power of $10 \mathrm{~kW}$ in a junction temperature range up to $200^{\circ} \mathrm{C}$. Output power density of more than $20 \mathrm{~kW} / \mathrm{L}$ was achieved. The design specifications, the power module fabrication process, the results of a high-temperature operating test and a continuous switching test are described in turn.

\section{Introduction}

There are various important requirements for $\mathrm{SiC}$ inverter and converter systems, including smaller size, lighter weight, greater availability, more robustness and lower cost. A promising approach that comprehensively meets all of them is to increase the output power density (OPD) of the system. In a higher OPD system, low on-resistance SiC power devices mounted on a small and simplified heatsink are operated at larger current densities and/or in extended junction temperature ranges. Recently, Kinouchi and his coworkers fabricated a $3.7 \mathrm{~kW} / 400 \mathrm{~V}$ three-phase all $\mathrm{SiC}$ inverter for motor drive applications [1]. However, their system was still comparable in OPD to a state-of-the-art Si-IGBT inverter [2]. This paper describes a forced-air-cooled $10 \mathrm{~kW} / 400 \mathrm{~V}$ threephase $\mathrm{SiC}$ inverter with an OPD of more than $20 \mathrm{~kW} / \mathrm{L}$ and a minimized heatsink volume [3] and capable of operating at junction temperatures ranging from room temperature to $200^{\circ} \mathrm{C}$.
\end{abstract}

\section{Configuration and Module Fabrication}

Figure 1 shows a full view of our $\mathrm{SiC}$ inverter system for motor drive applications. Figure 2 illustrates its circuit configuration. The system is composed of three 2-in-1-type power modules, individually equipped with $\mathrm{Cu}$ heatsinks, DC-link capacitors and cooling fans, and is $500 \mathrm{~cm}^{3}(15 \mathrm{~cm} \times 9 \mathrm{~cm} \times 3.7 \mathrm{~cm})$ in volume. $\mathrm{SiC}$ normally-off JFETs (SJEC120R050, $1.2 \mathrm{kV}, 30 \mathrm{~A}$ ) and $\mathrm{SiC}$ SBDs (SDC30120, $1.2 \mathrm{kV}, 30 \mathrm{~A}$ ) from SemiSouth Laboratories, Inc. were selected as the power devices. One arm consists of two JFETs and two SBDs. A dedicated gate drive and control unit was also fabricated (not shown).

Fig. 1 Photo of 3-phase all SiC inverter.
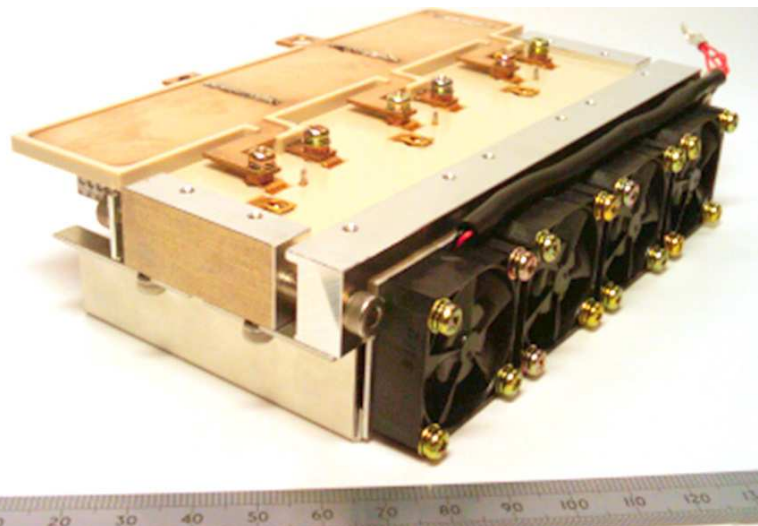


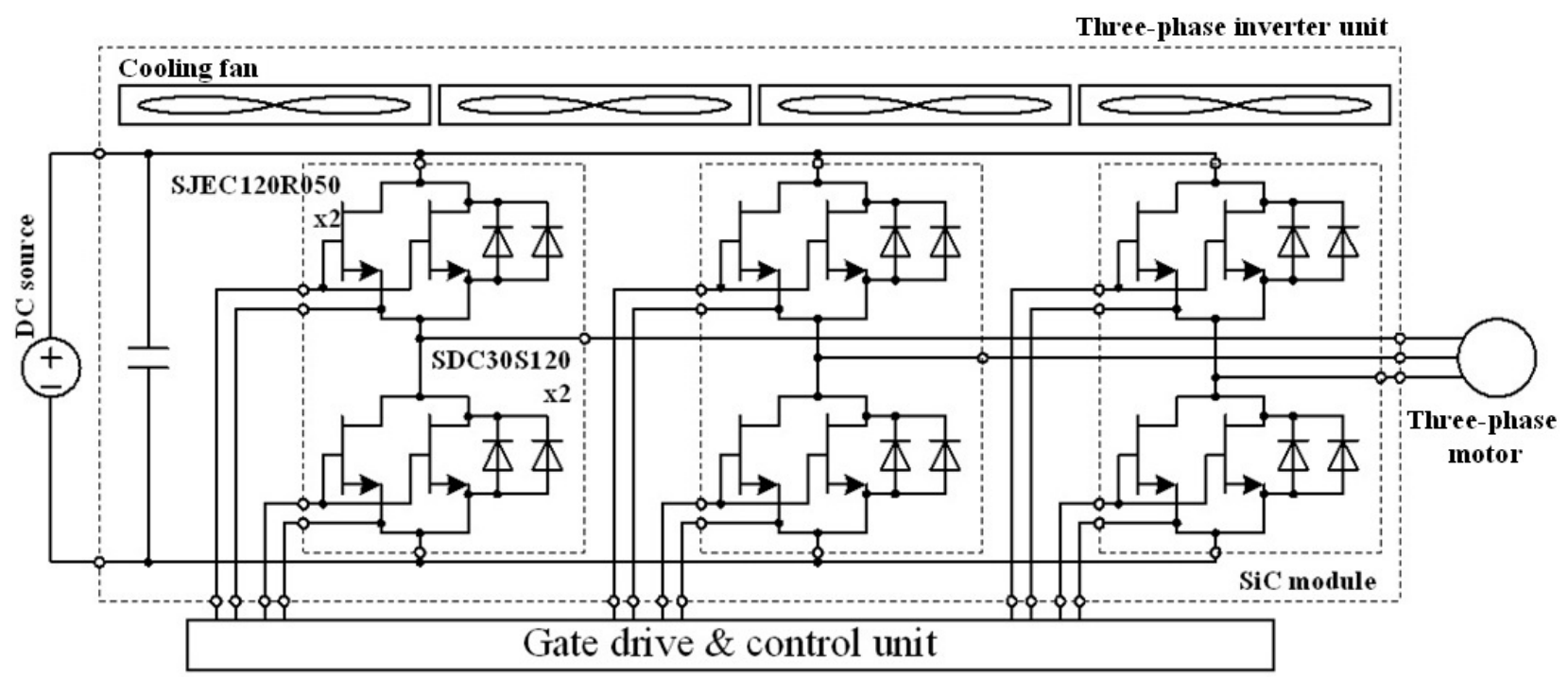

Fig. 2 Circuit configuration of three-phase all $\mathrm{SiC}$ inverter.

Figure 3 is a photograph of the power module. $\mathrm{SiC}$ devices for two arms were first soldered on $\mathrm{Ni} / \mathrm{Au}$ plated $\mathrm{Cu}$ foils on an $\mathrm{SiN}$ ceramic substrate using a Au-Ge alloy (melting point $=356^{\circ} \mathrm{C}$ ) [4], and the substrate was attached on a $\mathrm{Cu}$ heatsink using Au-Sn solder (melting point $=280^{\circ} \mathrm{C}$ ). Terminal pins for control signals were also attached in this second step. A heat-resistant silicone gel (ADEKA-BYX-001G) and a polyphenylene sulfide (PPS) resin were used as the encapsulation and housing materials, respectively.

\section{Operating Tests}

Figure 4 shows the current density distribution in two arms (a module) for the turn-on and turn-off transient. These results were calculated by using a Q3D parasitic extraction software tool. It is clear that the current through the JFETs and the SBDs (anti-parallel connected) was dispersed adequately. It was also found that the parasitic inductance between the DC terminals was $15.3 \mathrm{nH}$ per module.

Static and dynamic characterizations were carried out at module and various block levels. Typical turn-off and turn-on waveforms of the inverter at $\mathrm{Tj}=200^{\circ} \mathrm{C}$ are shown in Fig. 5, where the DC-link voltage and the switching current were $600 \mathrm{~V}$ and $30 \mathrm{~A}$, respectively. Figure 6 shows the drive circuit. To speed up the turn-on performance of the transistor, an additional circuit was used to supply a large current to the gate of the transistor in a short time at the beginning of the turn-on transient. To shorten the turn-off time, the gate was connected to $-12 \mathrm{~V}$ at the turn-

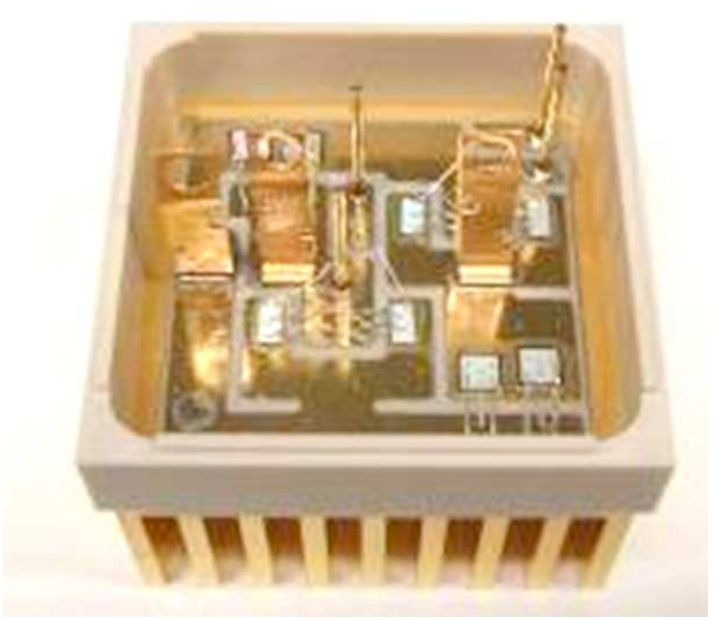

Fig. 3 Two-in-one-type SiC power module (2 arms). Four JFETs and four SBD chips are mounted on one SiN substrate.

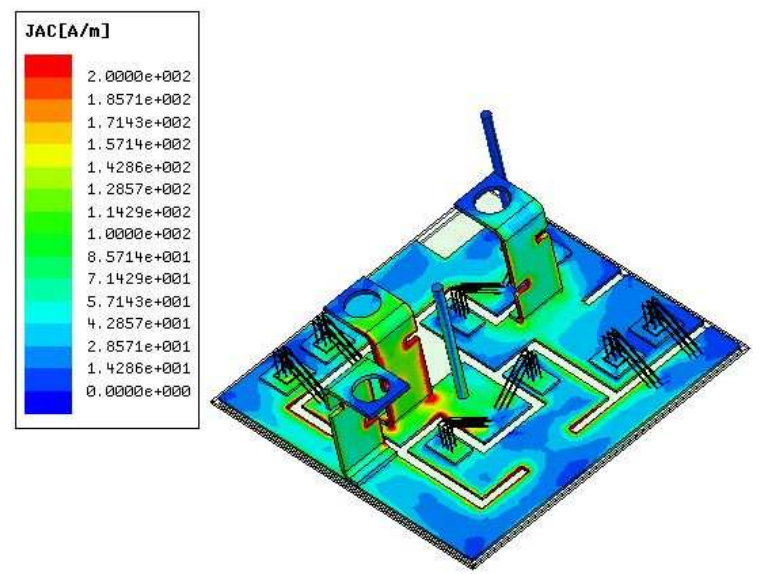

Fig. 4 Analysis results of current density distribution for the switching transient. 


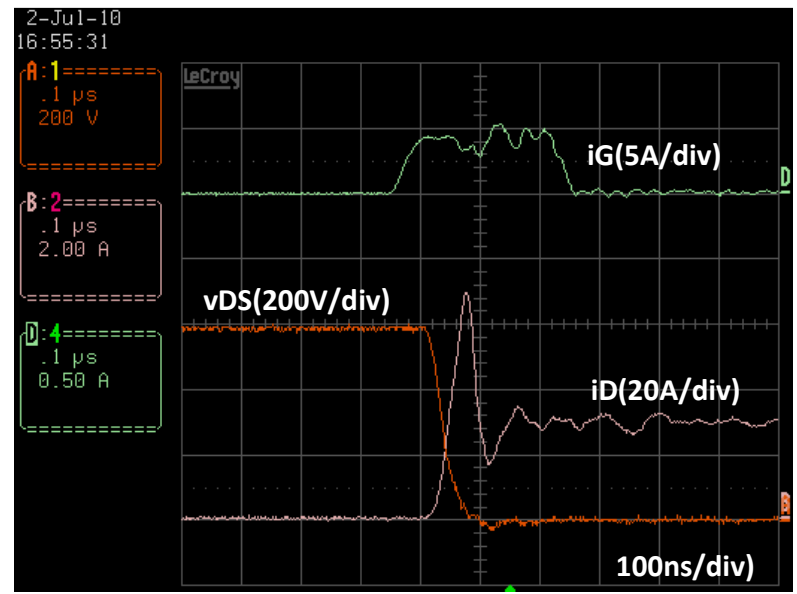

(a) Turn-on

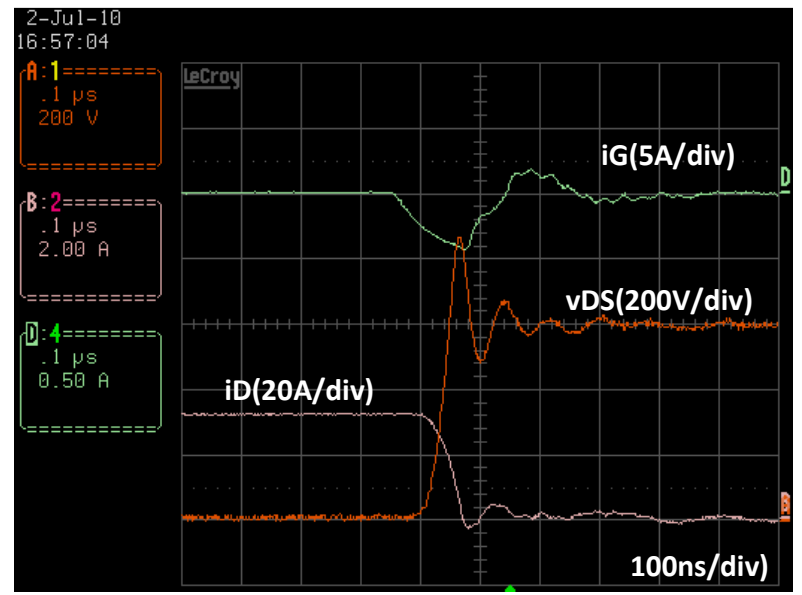

(b) Turn-off

Fig. 5 Switching behavior at $200^{\circ} \mathrm{C}$ for one arm of the module: (a) turn-on and (b) turn-off.

off transient. As a result, turn-on and turn-off times of 40 ns were achieved.

Figure 7 shows the setup of a continuous switching test using two power modules. The equivalent circuit is presented in Fig. 8. The active switching blocks, Q1 and Q4, were operated by the 90-degree phase difference. The load current $i_{\mathrm{L}}$ was kept constant by feedback control. The voltage $\left(v_{\mathrm{DS}}\right)$ and current $\left(i_{\mathrm{D}}\right)$ waveforms in Q1 are shown in Fig. 9. It is clear from these waveforms

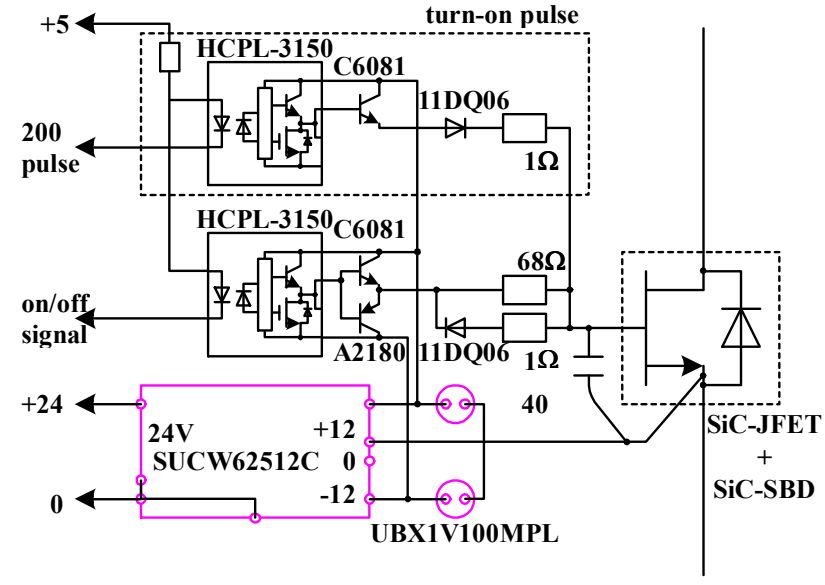

Fig. 6 Gate drive circuit with speed-up options used for measurement of the module in Fig. 3.

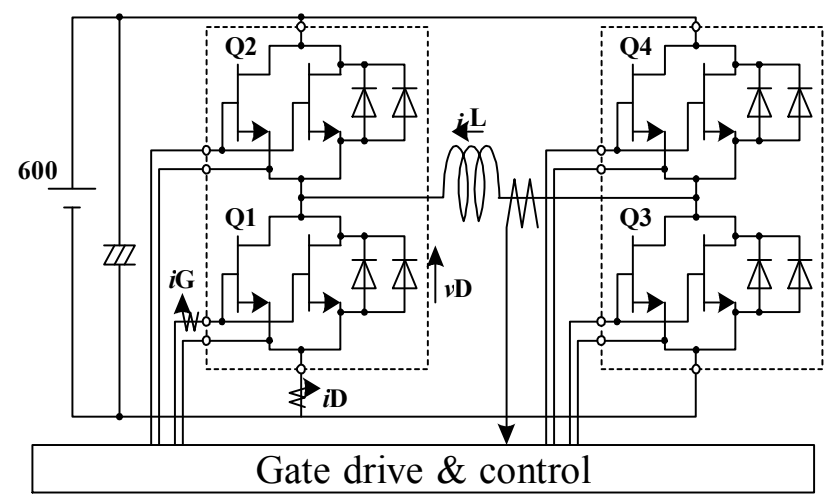

Fig. 8 Circuit configuration of setup in Fig. 7.

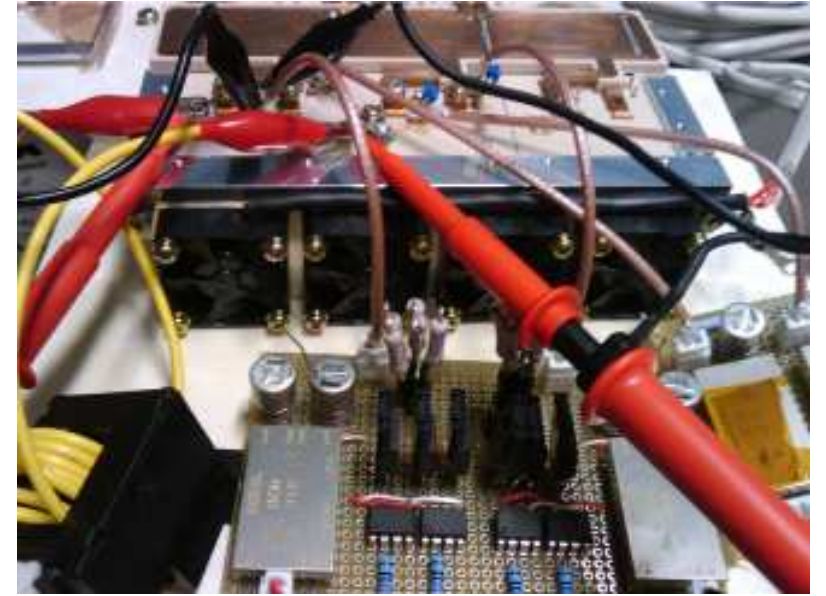

Fig. 7 Setup of the continuous switching test using two power modules.

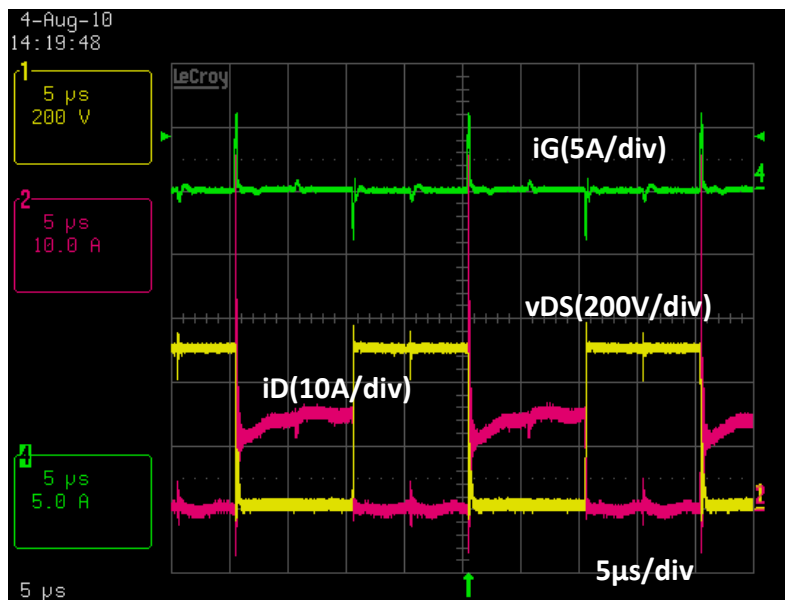

Fig. 9 Switching waveforms of setup in Fig. 7. 
that these test conditions induced the same level of switching stress as a $10 \mathrm{~kW}$ load condition in the three-phase inverter system. The cooling fin temperature was $100^{\circ} \mathrm{C}$ under the conditions of a 50 $\mathrm{kHz}$ switching frequency, $25^{\circ} \mathrm{C}$ ambient temperature and no forced air cooling. With forced air cooling using the fans shown in Fig. 1, the cooling fin temperature was $55^{\circ} \mathrm{C}$. The wind speed was 3 $\mathrm{m} / \mathrm{s}$, which was measured with a hot wire anemometer at the outlet. These results suggest that higher output power is attainable.

Figure 10 shows the waveforms of the output load current and the voltage across the active switching device under inverter operating conditions of a $50 \mathrm{kHz}$ switching frequency and dead time of $0.75 \mu \mathrm{s}$. The waveforms indicate that our inverter produces a fairly good sinusoidal wave.

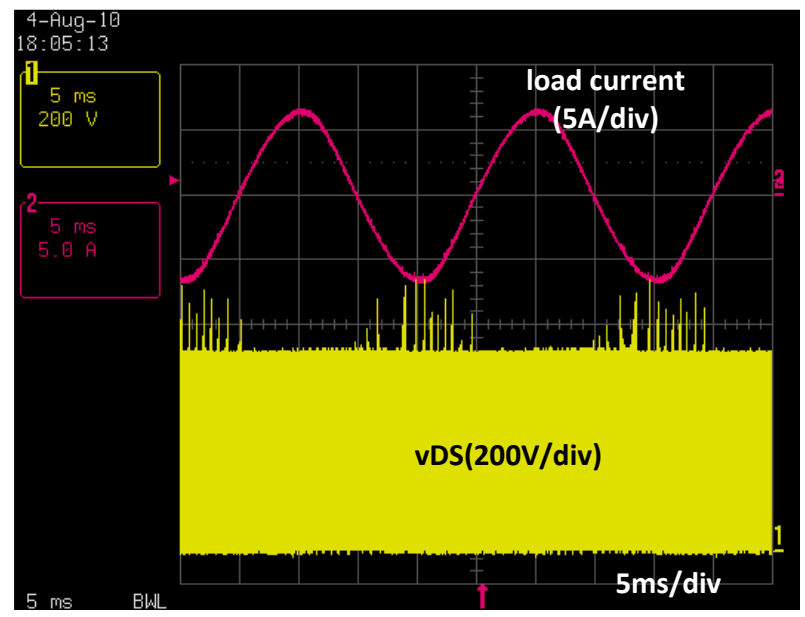

Fig. 10 Waveforms of the output load current and the voltage across the active switching device under inverter operating conditions.

\section{Summary}

A forced-air-cooled $10 \mathrm{~kW}$ three-phase inverter prototype, including three 2-in-1 type full SiC power modules, was designed and fabricated. SiC modules, $\mathrm{Cu}$ heatsinks, DC-link capacitors and cooling fans were enclosed in a volume of $500 \mathrm{~cm}^{3}$. An output power density of more than $20 \mathrm{~kW} / \mathrm{L}$ was successfully achieved. The system can operate stably at the rated power without any problem in a junction temperature range up to $200^{\circ} \mathrm{C}$. Regulated sinusoidal wave output power was stably observed for the single-phase full bridge circuit configuration. The parasitic inductance between the DC terminals was estimated to be $15.3 \mathrm{nH}$ per module. More detailed characterization is now in progress. New results will be reported elsewhere in the near future.

\section{Acknowledgment}

This work was supported by a grant from the Future Power Electronics Technology (Green IT) project directed by the New Energy and Industrial Technology Development Organization (NEDO) of Japan.

\section{References}

[1] S. Kinouchi, H. Nakatake, T. Kitamura, S. Azuma, S. Tominaga, S. Nakata, Y. Nakao, T. Oi and T. Oomori, Mater. Sci. Forum, 600-603, p. 1223 (2009).

[2] Y. Sakai, H. Ishiyama and T. Kikuchi, SAE Technical Paper Series, 2007-01-0271.

[3] K. Matsui, S. Sato, K. Takao, S. Tanimoto, Y. Murakami and H. Yamaguchi, Ext. Abst., IEEJ General Meeting (Mar. 2010, Tokyo), p. 226 (in Japanese)

[4] S. Tanimoto, Y. Murakami, M. Matsui, H. Yamaguchi and H. Okumura, Proceedings of International Conference on High Temperature Electronics 2010 (May 2010, Albuquerque, NM, USA) 